DOI: 10.20472/IAC.2018.039.040

SVEN OLAF SCHMITZ

Universidad Católica San Antonio de Murcia, Germany

\title{
BEYOND BUDGETING - A FAIR ALTERNATIVE FOR MANAGEMENT CONTROL? EXAMINING THE RELATIONSHIPS BETWEEN BEYOND BUDGETING, ORGANIZATIONAL JUSTICE AND UNETHICAL BEHAVIORS.
}

\begin{abstract}
:
The influence of Management Control Systems (MCS) on the social framework of organizations has been discussed in research and practice since the seminal work of Chris Argyris (1953). In this context, the impact of MCS design on unethical behaviors has been of particular interest. To remedy MCS related unethical behaviors some researchers developed Beyond Budgeting (BB) as an alternative MCS approach that is rooted in MCGregor's Theory Y. BB builds on specific MCS characteristics and its proponents claim that these characteristics are capable to reduce MCS related unethical behaviors. However, there has been quite little research on the underlying effect mechanisms of the relationship between the design of MCS characteristics and unethical behaviors. Recent research suggests that the design of MCS characteristics has a significant impact on organizational justice perceptions. Furthermore, organizational justice has been found to be positively correlated with various positive organizational outcomes, particularly trust and behavior. This study tries to contribute to deepen the understanding of the interplay between MCS design, organizational justice and unethical behaviors by applying structural equation modelling to examine these relationships. The results suggest that some MCS characteristics that are part of a BB design have a significant impact on organizational justice perceptions. Moreover, the results also suggest that the enhancement of organizational justice perceptions might finally lead to a reduction of MCS related unethical behaviors.
\end{abstract}

\section{Keywords:}

Management control systems; Ethics; Fairness; Justice; Trust; Behavior

JEL Classification: $A 13, A 14, M 14$ 